\title{
Barriers To Effective E-Business In Developing Countries
}

C. Patrick Fleenor, (E-mail: fleenor@seattleu.edu), Seattle University Peter Raven, (E-mail: pvraven@seattleu.edu), Seattle University

\begin{abstract}
The Internet has changed the way many firms do business in the U.S. and throughout the world. Practicing e-business in developing countries is particularly challenging for a number of reasons. In this paper we present a taxonomy of barriers facing e-businesses pursuing markets in developing countries. The major barriers center around culture, economic dimensions, infrastructure, and the political/regulatory environment. We identify key components of each barrier type. For example, cultural barriers include language, shopping habits, and use of credit, among others. Country specific examples are presented with management implications and possible solutions.
\end{abstract}

\section{Introduction}

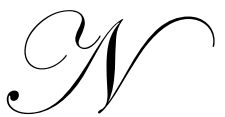

orth American firms are conducting more business over the Internet, but are missing important markets overseas. A North America-oriented Web site will reach only five percent of the world's population and 25 percent of global purchasing power, but few consumer websites generate any international revenue at all (Davenport 2000). While globalization is increasingly on the minds of progressive business executives, the nuances of global e-business are less obvious. This paper focuses not on the attractive industrial countries of the world, but on emerging economies. The importance of these emerging economies in the future of ebusiness will become obvious - and the time for strategic planning is now.

We use the term "e-business" to broadly describe the publishing of information and the performing of various transactions over the Internet, Extranets, or Intranets (Bakry and Bakry 2001). E-business includes the various terms used to express specific functions, including e-commerce, e-government, and others. The barriers to effective e-business are varied enough in the industrial world, but especially problematic in the developing world. Some obstacles are likely to be removed in the relatively near future, but others will remain over a much longer period. To help readers understand the nature of barriers to e-business, we first review the extent of e-business and expectations for the near future. We then examine a number of well-recognized barriers to e-business, and then focus specifically on individual developing and emerging economies. Finally, we propose some management implications for conducting e-business in emerging economies.

\section{Current E-Business}

More than fifty percent of the population in the United States is online, and most of the e-commerce conducted globally is North American based and will continue to be for the near future (Singh, Jayashankar, and Singh 2001). E-commerce in the developing world is another matter. Fewer than half the world's population has ever made a phone call (Hayden 2000, Rabe 2001). Two billion people subsist on less than $\$ 2$ per day, more than twenty percent of these have never heard a dial tone and no more than two percent are connected to the Internet (Romulo and Stofberg 2001). How can the information society be global? Despite the statistics, the online population of the world is expected to increase dramatically in the near future, with a shift toward non-English speakers (WTM 2001a). Still, this growth will come primarily in developed countries. These changes should not

Readers with comments or questions are encouraged to contact the authors via email. catch the smart e-business unprepared, but what do they mean for e-business in the future? 
The global economy today approaches $\$ 70$ trillion, but less than two percent of that is online. By 2004 the figure may exceed $\$ 110$ trillion, of which eight to ten percent will be online (Hayden 2000). Ninety percent of the U.S. firms surveyed by Forrester Research plan to buy and sell on the Internet (Bingi, Mir, and Khamalah 2000). This represents a dramatic shift not only in size, but also in the nature of global business. Political borders will be less significant to the mobility of capital, and time differences no longer pose a problem to conducting business. Currently successful business models that do not adjust may be rendered obsolete. Analysts seem to agree that in the new economy, successful global e-businesses will employ a more collaborative business model (WTM 2001b). Successful on-line retailers will likely be those that have both physical stores and Web sites - known as the "clicks and bricks" model (McKinsey 2001a).

Currently, about 378 million people are online, with 161 million in North America, 106 million in Europe, 90 million in Asia/Pacific, 15 million in Latin America, 3 million in Africa, and 2.5 million in the Middle East (Romulo and Stofberg 2001). The digital divide is represented by these figures and is of concern to many, including the G8, which recently took steps to ensure the world's poorest countries will share in the benefits of free electronic commerce. A result of this concern is the Global Business Dialogue on Electronic Commerce (GBDe), which was formed by 72 companies in diverse countries. Their objective is to work in cooperation with businesses, governments, NGOs, and others in helping create an environment that ensures e-commerce will reach its economic potential. E-commerce may offer the possibility for emerging economies to leapfrog their development.

\section{Barriers to E-Business}

Successful e-business depends on a critical threshold of online users, the precursor to a critical threshold of sellers and buyers. This critical threshold has evidently been reached in North America and Scandinavian countries, but has not progressed much beyond those regions (Krück and Papenbrock 2000). While it is not a precisely defined phenomenon, this critical threshold can be likened to Metcalfe's Law, which explains that the value of a network increases with the square of the number of participants (Hanson 2000). This suggests that as more people go online, the value of the whole network and the opportunities for e-business increase tremendously. Clearly, if only a few people are online, the opportunities for exchange are limited, but if many are online, the opportunities increase dramatically. It is important to have many people online for e-business to work well.

What will it take to increase the global online population? Examining the North American and European situations may give us some clues. Effective e-business requires a number of factors, not all of which exist in most markets. We must examine the major barriers of personal computer penetration, inadequate infrastructure, politi$\mathrm{cal} /$ cconomic issues, cultural issues, and marketing issues in some detail.

\section{Personal Computer Penetration}

Personal computer (PC) penetration is arguably the prime indicator of readiness for e-business. There is a direct relationship between PC penetration and e-commerce (Rabe 2001; Singh, Jayashankar, and Singh 2001). PC ownership is also related to income (Polster and Trinh 2000). This is clearly a major consideration for developing countries. A low-end PC in China may cost only USD 450, a bargain by our standards, but that represents more than two months wages for the average Internet user (Rabe 2001). Even within a region, PC penetration is highly variable. For example, in Thailand and the Philippines there are about 20 PCs per thousand people, compared with 510 in Singapore. In China, with a population of 1.3 billion, only 20 million own PCs. This relationship between income and PC ownership, while obvious, is complicated by many other factors, not the least of which is inadequate infrastructure to support Internet connections.

\section{Infrastructure}

Even as PC costs have declined, access to an Internet connection eludes most people in developing countries. Inadequate infrastructure plays a key role in inhibiting e-business globally. Issues such as access to Internet services, including the hardware and software, as well as the communications infrastructures, remain serious ob- 
stacles to e-business in many developing countries (Panagariya 2000). In much of Africa, for example, the infrastructure is so poorly developed that it will likely take years for the average citizen to benefit from e-commerce. In Asia, there is such a disparity in the infrastructure that PC penetration rates range from only 20 per 1000 in Thailand to 43 in Malaysia to more than 500 in Singapore (Polster and Trinh 2000).

The cost of being connected, typically through telephone lines, is another aspect of infrastructure (WTM 2001a; Rabe 2001). Crispin (2000) indicates that government policies can severely hinder e-business. In Thailand for example, all long distance telephone and Internet connections pass through the Communications Authority of Thailand (CAT), a monopoly resulting in limited choices, high fees, and historically poor service. Even the industrial countries of Europe experience a wide disparity of connection charges. Except for Finland and Denmark, all other European countries pay much higher connection fees than in the US, where the average is $\$ 25$ per month for unlimited access. In France, Internet charges average $\$ 45$ a month and in Germany $\$ 68$ for just 20 hours. These prices are due partly to telephone monopolies and price gouging (Singh, Jayashankar, and Singh 2001). In addition, many telephone systems charge a toll per unit of usage. The combination of connection charges and use charges tend to inhibit the usage of the Internet in many countries and by extension reduces e-commerce activity.

\section{Economic/Political/Business Issues}

Much of the consumer world still pays by cash, rather than credit. The lack of ability or interest to execute credit transactions is an enormous barrier to e-commerce. There have been a number of innovative approaches to solving this problem (WTM 2001c), but until credit cards become ubiquitous or new payment methods emerge, ecommerce transactions will be hindered.

The issues of security of transactions and privacy protection over the Internet are of concern to many consumers. One of the authors, informally polling a group of 40 French MBA students, found only three who had purchased a product or service online. The remaining 37 cited security and privacy as the prime reasons they avoided purchasing online. Not only do industries have a role in providing security, but also governments, with suitable regulations, must assure it (OECD 1997). Digital signatures and other authentication procedures should be helpful in protecting privacy and personal data, but education is also important.

\section{Culture}

Culture and sensitivity to cultural differences plays a critical role in successful international business, and just as much so for international e-business. Understanding how the Web fits into a country's culture is necessary to forming successful customer relations (Rasmusson 2000a). Sites targeting foreign consumers should appear friendly to them, which likely requires translating the site into the local language. Eighty percent of web content is now delivered in English, but almost half of current users do not read English or they prefer to use their own language (Shannon 2000). As more non-English speakers go online, translating sites into local languages becomes increasingly important for e-business. A well-translated site will likely pay for its cost many times over in increased revenue.

Different languages and cultural platforms compound the complexity of doing e-business overseas, but a bigger barrier may well be the attitude and culture of business and government entities, which must lead consumers to learn what to expect from e-business (Singh, Jayashankar, and Singh 2001). For example, many European CEOs understand the power of the Internet, but fail to fully exploit it. They see the Internet more as a tool for improving existing business models, rather than a revolutionary device requiring a completely different mindset. In the end they may be proved correct, but this attitude may partially account for the uneven acceptance and use of the Internet even in industrial Europe.

In addition to language, other cultural behavior such as risk aversion and lifestyle differences may impact success on the Web (Singh, Jayashankar, and Singh 2001). The use of Hofstede's (1983) cultural dimensions can help e-businesses better understand their customers. For example, cultures rating high on uncertainty avoidance and low on individualism are likely to be difficult markets for introducing consumer e-business. 


\section{Marketing Issues}

A wide variety of marketing issues confront the global e-business. Among the more general are included relevant content for the market, form of business (B2B/B2C), fulfillment issues, and ethical issues. Given that for many markets the language must be consistent with that spoken locally, it is also important to assure that the content is appropriate and relevant (Bacheldo 2000; Rabe 2001). This may be much more difficult than merely translating from English to another language. In fact, relevancy is so important, it may require a professional consultant from the target country to assure that it is consistent with the culture.

The form of the e-business is crucial to success. While in the U.S., business-to-consumer (B2C) websites are common, business-to-business (B2B) activities are probably more appropriate for most emerging markets. The B2B market is expected to grow by ninety percent by 2004 (Meehan 2000). In Asia, B2B will likely outweigh B2C by ten to one (Polster and Trinh 2000). This is due to a number of factors, not the least of which are low purchasing power of consumers, fragmented markets, many different languages, undeveloped payment systems, and logistical problems. These obstacles make it much more difficult for B2C to occur.

E-businesses interested in B2B are well advised to partner with local firms to help in their expansion overseas (Bacheldo 2000). Partnering offers a number of advantages, including speed and understanding of local culture and business practices, but it also can complicate matters. It is especially important to screen potential partners.

Logistic and fulfillment issues make it especially difficult to take a domestic e-retail business overseas. Tariffs, different currencies, customs regulations, language, and return rates on international shipments, which can be as high as thirty to fifty percent, impede a firm's ability to ship overseas (Economist 2000, Sapp 2000). In consequence, many U.S. firms no longer take foreign orders. In a recent Forrester Research survey, forty-six percent of the interviewees indicated they turn away international orders because they do not have processes in place to handle them (Shannon 2000). Address verification may be difficult (Sapp 2000), which increases the risk of fraud in noncredit card transactions. It is also quite difficult to estimate changes in demand by customers and to determine the amount of inventory in the channels of distribution (Sowinski 2001).

Finally, we turn to an often overlooked issue, that of e-business ethics. In this new e-business environment, management is required to adapt to a more collaborative, corporate-competition model, which presents new challenges to traditional business ethics (WTM 2001b). In the "older" model of business ethics, firms were often considered isolated, competing with every other firm in a rather hostile business environment. This seemed to provide justification for any number of predatory practices and encouraged maximization of short-term advantage. Today, businesses conducting B2B e-business globally often partner with foreign firms (Bacheldo 2000), which requires opening themselves to various types of scrutiny and sharing sensitive information. In modern business ethics, the network relationship is highly valued and trust becomes a critical value, without which firms may be deliberately excluded from e-business opportunities. "Going 'open Kimono' exposes your partner to valuable information about your organization, information that could be inadvertently passed on to your competitors" (WTM 2001b). Besides carefully screening partners, astute e-businesses should establish a firewall around their mission critical information and intellectual property. Indeed, what information to share and what to withhold is a strategic issue.

\section{Vignettes From the Real World}

To illustrate some of the issues discussed before, we now turn to emerging markets that demonstrate some of the complexities, but also the opportunities of global e-business. Our examples begin in Asia/Pacific, and then turn to Latin America, Eastern Europe, and finally Africa and the Middle East.

\section{Asia/Pacific}

As the region with probably the most potential for e-business, Asia, especially the Asia/Pacific region, also 
represents significant challenges. The economic and cultural diversity within the region present unique problems, but the opportunities of a large population, increasing connectivity, and rapid though spotty growth in incomes, also beckon. The Asian "Tigers" of Taiwan, Singapore, South Korea, and Hong Kong lead the region in connectivity and e-business. We discuss these countries briefly to present a picture of the great diversity in the region and then proceed to the emerging e-markets of China, Thailand, India, and Vietnam.

Asian Tigers: A relatively high percentage of the population in these countries has Internet access, some approaching the level of the United States and Western Europe, but e-commerce lags the U.S. For example, 41 percent of South Koreans are connected, 34 percent in Hong Kong, 32 percent in Singapore, and 29 percent in Tai wan (Rabe 2001). However, even in the technology-obsessed cities of Singapore and Hong Kong, Internet retailing has not taken off (McKinsey 2001a). Shoppers may window shop online, but prefer to buy in stores. Culturally, shopping appears to be an enjoyable pastime, having both entertainment and social value. Only eight percent of Internet surfers in Hong Kong purchased online in December 2000 and five percent in Singapore (McKinsey 2001a).

The majority of Asian firms are just beginning to take the steps necessary toward purchasing online and are still further from selling their products online (McKinsey 2001b). Many Asian firms have noninteractive Web sites simply offering static information or brochure ware.

South Korea is one of the more electronically advanced countries, with Internet connectivity at forty percent of households and broadband rates higher than in the U.S. (Dodgson 2001). These rates are much greater than the twelve percent Internet connection level in Japan (Krück and Papenbrock 2000).

Asian governments have often relied on industrial policy to build specific industries, such as the automotive industry in South Korea. To build e-business, South Korea has adopted the "Cyber Korea 2" program to improve its IT infrastructure and raise the number of IT firms eightfold to 40,000 by 2005 . This initiative is expected to contribute eighteen percent to the Korean GDP (Polster and Trinh 2000). The Singapore government has invested more than USD 1.5 billion in the development of an e-government to provide citizens with more than 200 government services online (see http://www.gov.sg). Even Malaysia has set up a Multimedia Supercorridor (MSC) to improve competitiveness. However, the governments of China, Thailand, Indonesia, and India are lagging behind in their support of e-business.

China: Asian online firms largely confine their business to their home markets to avoid currency exchanges, high shipping costs, and delays in delivery. But China is one place where e-shopping will likely have a bright future. E-commerce volume is currently low in China ( $\$ 92$ million in 1999), but expected to grow to $\$ 5$ billion by 2005 (Polster and Trinh 2000). Chinese e-tailers find imaginative ways to get around otherwise insurmountable obstacles, but most will be successful with a combination of physical and online stores - the "clicks and bricks" model (McKinsey 2001a).

Since the Internet began to take off in China in 1998, two key bottlenecks seem to restrain the growth of ecommerce: problems with online payment and difficulties with distribution and fulfillment (Lawrence 2000). Some solutions have been offered, but they tend to be piecemeal fixes, rather than complete solutions. Cash on delivery services have overcome the payment issues to some extent and online payment is also becoming easier. For example, Shanghai Huateng Software Systems Co. recently spun off Chinapay.com, which provides an online payment system for Shanghai (Lawrence 2000). GNET offers an online payment system in Guangzhou and Cyber Beijing offers online payment in Beijing, but not in real time. Part of the problem with online payment in China has been not the use of credit per se, but that credit cards were tied to specific banks in the cities where the accounts were located. This, of course, reduced mobility and use for online payments.

An encouraging sign in China has been the shift in both disposable incomes and attitudes. Compared to five years ago, urban Chinese are investing and embracing new buying habits, including tele shopping. Five years ago, urban dwellers spent almost 64 percent of their income on daily necessities, but with more income today, there has been a shift in spending patterns and less than 50 percent is now spent on daily necessities (China.org.cn 2001). Five years ago, 53 percent of Chinese indicated they did not like the idea of buying on credit, but today that rate has 
dropped to 27 percent. Clearly, these financial and attitudinal changes bode well for the growth of e-commerce in China.

E-businesses attempting to market to China, however, must be aware of government controls and restrictions. The Chinese government maintains relatively restrictive control over Internet content, especially if it is deemed to be subversive or a threat to national security. These terms are vaguely defined and left largely to the whim of bureaucrats. Recently, Yahoo! carried a story about doctors harvesting the organs of Chinese prisoners, but the story was not carried on the Chinese Web page prepared in Beijing because of fears of government reaction (Yee 2001). These fears are not without merit. Dissident Huang Qi was recently tried for publishing writings about democracy on the Web amid the Chinese government's determination to stamp out online dissent. Also, the government has recently cracked down on "wangba," Internet bars that the government fears are providing forums for political dissent (Leicester 2001).

Thailand: The commercial use of the Internet in Thailand is hampered a great deal by the Communications Authority of Thailand (CAT) (Crispin 2000, Rabe 2001). Monthly charges for a dedicated Internet connection are about three times that in Malaysia and the Philippines at about 900 baht (USD20) for 20 hours per month (Business in Thailand Magazine 1999). Also, the PC penetration rate is very low (two percent). These barriers, added to a tradition of opaque bureaucracy and government controls over national resources, inhibit the growth of e-business in Thailand and place it at the low end of the competitive spectrum in S.E. Asia. International Data Corp. (IDC) indicates e-commerce accounts for only .04 percent of GDP in Thailand and most of that is through private networks due to the high costs (Crispin 2000).

Indonesia: Indonesia restricts foreign investment in the multimedia sector (Rabe 2001). While one of the region's largest in population, only 1.3 percent of Indonesians are connected to the Internet (Polster and Trinh 2000). Given the country's severe economic and political turmoil, rapid improvement is unlikely.

India: The connectivity rate in India is also very low (one percent) (Rabe 2000). However, the costs of being online are being reduced and competition for online services is increasing. Recently, the telecommunication firm Videsh Sanchar Nigam, or VSNL, reduced its charges by forty percent (McKinsey 2000b).

Vietnam: With a hard-working, resourceful populace, and abundant natural resources, Vietnam has tremendous growth potential (Walsh 2001). In 1998, PC penetration was less than one percent in this country of 75 million, but the government plans to raise this to twenty percent by 2010 (IDG.net 2000). Still quite low, Internet access has jumped from 14,500 the first year of access in 1997 to about 45,000 in 2000. Connection costs run about VND 45000 per month (USD 30) and registration is VND 270,000 (USD 180), plus there is a connection charge that varies depending on day and user of about VND 290 per minute (USD 0.19) and a ten percent VAT (Geiser 2001). Local and foreign businesses are still frustrated by government restrictions. However, a number of partnerships formed by the Vietnam Post and Telecommunications Corp. (VNPT) and Cable \&Wireless, Nippon Telephone and Telegraph, and France Telecom promise to expand connectivity by 400,000 fixed lines per year in Hanoi and Ho Chi Minh City (IDG.net 2000). Also, VNPT has signed with Australia's Telstra to integrate cellular phone operations. Three competing factors will tend to influence e-commerce in Vietnam in the short term: 1) the government's interest in enabling citizens to benefit from e-commerce; 2) concern about the negative effects of the Internet's open structure on the traditionally close-knit Vietnamese society; and 3) the need to maintain high profits to continue investing in Internet infrastructure. To those can be added the challenges of underdeveloped legal and banking systems that will allow e-commerce to thrive.

Latin America: Like its Asian counterparts, there are wide disparities in PC penetration and Internet connectivity in Latin American countries. The number of Internet users is rising faster in Latin America than in any other region of the world (Perez 1999). Latin American users are expected to grow from about fifteen million to nineteen million by 2003 (Heckman 2000; Romulo and Stofberg 2001) and IDC expects e-commerce in the region to reach $\$ 8$ billion by that time. Today, though, many Latin American net users actually prefer to use U.S. ecommerce sites to those in their own countries because of their perceptions of trust, convenience, and low prices (Rasmusson 2000b). 
Brazil leads the way in Latin America, with 1.7 million Internet subscribers, but free Internet access is now available from a number of ISPs (e.g., Internet Gratis company), even though many Brazilian ISPs are still quite dependent on access fees for revenue (National Trade Data Bank 2000). This aggressive step toward reducing the digital divide in Brazil could more than double the number of Brazilian households able to afford Internet access. One Sao Paulo consulting group estimated that the online population in Brazil could jump from seven to seventeen percent if cheaper PCs and lower access costs were introduced. This seems to be occurring.

Eastern Europe As an indicator of e-business in Eastern Europe, Russia suggests the problems and the possibilities. Next year more than two percent of Russians will begin using the Internet. This country is struggling with outdated infrastructure and low penetration of telecommunication lines. About six percent of the population (6.6 million people) are connected, with the highest penetration in Moscow and St. Petersburg. However, almost 78 percent of Russians surveyed by the Monitoring.ru Group indicate they are not now using the Internet and do not expect to in the near future. Almost seventeen percent of Russians do not have the technical or financial means to use the Internet and almost 67 percent are simply not interested in using it (Monitoring.ru 2001).

As a cash society, credit cards are not often used for payment. However, Avtocard Holding, a Moscowbased payment-processing firm, is pioneering an online payment card said to be the safest and simplest option for Russians leery of banks and credit cards (Monitoring.ru 2001). Growth is wireless telephony has been spectacular with cellular networks experiencing 100\% growth in both 1999 and 2000. This new sector has some intrinsic appeal in that it is not encumbered with an outdated legacy infrastructure with archaic regulations.

Africa and the Middle East PC and Internet penetration are very low in these regions - with about 3 million online in Africa and 2.4 million in the Middle East (Romulo and Stofberg 2001). Infrastructure and services are minimal. Sometimes, connections between users in two African countries must pass through the U.S. (Bingi, Mir, and Khamalah 2000). The demand and supply is so low in the poor countries of Africa that e-commerce will likely take a long time to benefit these countries (Panagariya 2000).

\section{Conclusion and Managerial Implications}

It is apparent that the Internet and e-business have changed the way firms do business globally. The adoption of the Internet has occurred at a faster rate than any previous technology, but the Digital Divide demonstrates that these changes have not occurred uniformly throughout the world (Jiang et al. 2000). It has occurred so rapidly in the developed world that scholars have been unable to keep pace with their research and relatively little empirical work has studied the phenomenon. However, the work that has been done suggests that a systematic approach to examining the global marketplace for e-business is possible.

E-business strategies are one more requirement heaped on the plates of struggling developing countries to prevent their isolation and loss of competitiveness. As with any strategy, success requires setting objectives, developing knowledge and training, enabling technology, redesigning business processes and regulations, identifying security issues, staffing, migrating from business to e-business, cooperating with other organizations, continuous management development, and integrating these plans (Bakry and Bakry 2001).

Understanding the adoption rates of technology is a prerequisite in increasing the use of the Internet. The Technology Acceptance Model (TAM) has been applied to the utilization of the Internet and is described by Jiang et al. (2000). This model, which has been empirically tested, suggests that utilization of the Internet is positively related to four important indicators, perceived near-term usefulness, perceived long-term usefulness, prior experience, and facilitating conditions. Experience is an important driving force that seems to relate back to our understanding of the value of a network and Metcalfe's Law. As more and more people around the world get online, they perceive the value of doing so to increase. What can be done to facilitate the online experience in emerging economies?

PC penetration (related to income) and inadequate infrastructure have been earlier identified as significant barriers to e-business in developing economies. Overcoming these obstacles should allow more people to go online. 
Conquering poverty in developing economies is probably not realistic in the short-term, but a logical goal for the long-term. In the meantime, new technologies may well facilitate the online experience, especially mobile communications.

Mobile telephony is already huge in Asia, which is well positioned for m-commerce (Krück and Papenbrock 2000). Already ten percent of the population in Asia's emerging economies uses mobile telephones, with Japan and China likely to be especially high growth areas. By the end of 2001, mobile phone penetration in Hong Kong and Singapore could reach 75 to 85 percent, and in China 10 percent (Rabe 2001). The slow transfer rates of today's mobile telephones will be improved when third generation $(3 \mathrm{G})$ systems are implemented.

The future for e-business in some emerging economies is bright, while others will struggle to become successful. In this paper we attempted to identify some of the critical issues for successful e-business in these developing economies and to aid managers in understanding the differences in how countries have approached e-business and the new economy. Clearly, countries like China will outpace those such as Thailand, Indonesia, and India in progressing toward efficient e-business. However, it will probably pay astute e-business managers to consistently scan the developing economies for opportunities, as things can change rapidly in this new economy, especially when the incentives and pressure to do so are so great.

The authors are listed alphabetically having contributed equally to the paper. The authors thank the Institute for Global e-Business (IGBI) at Seattle University for support on this paper.

\section{References}

1. Bacheldo, Beth (2000), "Worldwide e-Commerce: It's more than a Web Site," Informationweek, 785, 4748.

2. Bakry, Saad Haj and Fahed Haj Bakry (2001), "A strategic view for the development of E-Busiiness," International Journal of Network Management, 11, 103-112.

3. Bingi, Prasad, Ali Mir, and Joseph Khamalah (2000), "The Challenges Facing Global E-Commerce," Information Systems Management, 17, 4 (Fall), 26-34.

4. Business in Thailand Magazine, December 1999, www.businessinthailandmag.com, downloaded 8/25/01.

5. China.org.cn (2001), Website on China News, http://www.china.org.cn/english/16952.htm, accessed 8/03/01.

6. Crispin, Shawn W. (2000), "E-commerce Emasculated," Far Eastern Economic Review, September 21, http://www.feer.com/_0009_21/p26region.html, accessed 4/26/2001.

7. Davenport, Tom (2000), "E-Commerce Goes Global," CIO, 13, 20 (August 1), 52, 54.

8. $\quad$ Dodgson, Charles (2001), "Why Korea?" Communications International, June, B20.

9. Economist (2000), "Survey: E-Commerce: First America, then the World," Economist, 354, 8159 (February 26), S49-S53.

10. Geiser, Peter (2001), 'Peter M. Geiser's Internet Travel Guide internet access," http://www.pmgeiser.ch/vietnam/general/internet.htm.

11. Hanson, Ward (2000), Internet Marketing, South-Western College Publishing, a division of Thomson Learning: Cincinnati, $\mathrm{OH}$.

12. Hayden, David (2000), "The Internet Is A Domain Of Thinking And Acting: Leadership in the ECommerce Revolution," Vital Speeches of the Day, 66, 16 (June 1), 496-500.

13. Heckman, James (2000), “'International' in Internet closes U.S. lead," Marketing News, 34, 4 (February 14), 7-8.

14. IDG.net (2000), http://www.idg.net/

15. Jiang, James J., Maxwell K. Hsu, Gary Klein, and Binshan Lin (2000), "E-commerce User Behavior Model: an Empirical Study," Human Systems Management, 19, 265-276.

16. Krück, Ursula and Klaus Papenbrock (2000), "Regional Starting Positions in Global E-Competition," Deutsche Bank Research, May 22.

17. Lawrence, Susan V. (2000), "Linking Up,” Far Eastern Economic Review, August 24, http://www.feer.com/_0008_24/p42innov.html, accessed 4/26/01. 
18. Leicester, John (2001), "China cracks down on Internet," Seattle Post-Intelligencer, August 18, A5.

19. McKinsey, Kitty (2001a), "Shoppers Lost In Cyberspace," Far Eastern Economic Review, Feb 22, http://www.feer.com/_0102_22/p034innov.html 2001, retrieved Feb. 17, 2001.

20. McKinsey,Kitty (2001b), “Asians Miss The E-Biz Mark," Far Eastern Economic Review, March 15, http://www.feer.com/_0103_15/p042innov.html, Accessed 4/26/01.

21. Meehan, Michael (2000), "Foreign Markets Draw B-to-B Firms Overseas," Computerworld, 34, 20 (May $15), 40$.

22. Monitoring.ru (2001), "Monitoring.ru Group" website, http://eng.monitoring.ru, accessed 8/03/01.

23. National Trade Data Bank (2000), "Brazil: Free Internet Access Hits with a Vengeance," U.S. Department of Commerce, November 3, http://www.tradeport.org/ts/countries/brazil/.

24. OECD (1997), "Dismantling Barriers to Global Electronic Commerce," http://www.oecd.org/dsti/sti/it/ec/prod/dismantl.htm, accessed 4/26/01.

25. Panagariya, Arvind (2000), "E-Commerce, WTO and Developing Countries," The World Economy, 23, 8 (August), 959-978.

26. Perez, Juan Carlos (1999), "PSINet buys Argentina ISP,” IDG News Service, July 13, http://www.idgnet.com/.

27. Polster, Rainer and Tram Trinh (2000), "Emerging Asia: from Hardware Base to E-commerce Space?" Deutsche Bank Research, No. 9, November 7.

28. Rabe, Jens (2001), "The Digital Divide - focus on Asia," Deutsche Bank Research, No. 17, August 15.

29. Rasmusson, Erika (2000a), "E-Commerce around the World," Sales and Marketing Management, 152, 2 (February), 94.

30. Rasmusson, Erika (2000b), “Targeting Global E-Customers," Sales \& Marketing Management, 152, 1 (January), 78.

31. Romulo, Bobby and Cobus Stofberg (2001), "Building Digital Bridges: the Global Business Dialogue on Electronic Commerce," The OECD Observer, No. 224 (January), 27-28.

32. Sapp, Geneva (2000), "Vendors Tackle Global Trade," InfoWorld, 22, 7 (February 14), 16.

33. Shannon, Paula (2000), "Including Language in your Global Strategy for B2B e-Commerce," World Trade, 13, 9 (September), 66-68.

34. Singh, Tanuja, Jay V. Jayashankar, and Jasvinder Singh (2001), "E-Commerce in the U.S. and Europe -Is Europe Ready to Compete?" Business Horizons, 44, 22 (March-April), 6-16.

35. Sowinski, Lara L. (2001), "International E-commerce Fulfillment," World Trade Magazine, Global Online, 05/17/2001, http://www.worldtrademag.com/CDA/ArticleInformation/news/news_item/0,3881,26433-20860,00.html, (Accessed July 29, 2001).

36. Walsh, John K. (2001), "Special Edition Global Review 2001," U.S. Bank Global Markets Update.

37. WTM (2001a), "Beyond Multilingualism," World Trade Magazine, Global Online, Posted on: 06/14/2001, http://www.worldtrademag.com/CDA/ArticleInformation/Global_Online_Item/0,3509,28125,00.html, accessed 8/03/01.

38. WTM (2001b), "New Corporate Ethics for the New Economy," World Trade Magazine, Global Online, $02 / 27 / 2001$,

http://www.worldtrademag.com/CDA/ArticleInformation/Global_Online_Item/0,3509,21606,00.html, accessed 8/03/01.

39. WTM (2001c), "Paying International Bills over the Internet," World Trade Magazine, Global Online, $02 / 27 / 2001$,

http://www.worldtrademag.com/CDA/ArticleInformation/Global_Online_Item/0,3509,21600,00.html, accessed 8/03/01.

40. Yee, Chen May (2001), “In Asia, It’s Not a Wide-Open Web,” Wall Street Journal, July 19, B1.

Notes 
